\title{
The role of personality, cognition, and affective state in same-sex contests in the red junglefowl
}

\author{
Laura Clare Garnham ${ }^{1}$ (D) $\cdot$ Sabina Ahlgren Porthén ${ }^{1} \cdot$ Sarah Child $^{1,2} \cdot$ Sara Forslind $^{3}$ (D) $\cdot$ Hanne Løvlie $^{1}$ (D)
}

Received: 28 June 2019 / Revised: 11 October 2019 / Accepted: 17 October 2019/Published online: 19 November 2019

(C) The Author(s) 2019

\begin{abstract}
Intra-species contests are common in the animal kingdom and can have fitness consequences. Most research on what predicts contest outcome focuses on morphology, although differences in personality and cognition may also be involved. Supporting this, more proactive individuals often have dominant status, although the causality of this relationship is rarely investigated. Contest initiators often win; thus, individuals that are more proactive in their personality (e.g., more aggressive, risk-taking) or cognition (e.g., more optimistic, impulsive) may initiate contests more often. To investigate this, we assayed the behavior and cognition of sexually mature male and female red junglefowl (Gallus gallus), a species in which both sexes contest over social status, before staging intra-sexual contests. We confirm that contest initiators were more likely to win. In males, individuals that behaved more boldly in a novel arena test were more likely to initiate and win contests. Female initiators tended to be less active in novel object test, more aggressive in a restrained opponent test, and respond less optimistically in a cognitive judgement bias test, whereas the main predictor of whether a female would win a contest was whether she initiated it. These results suggest that behaviors attributed to proactive and reactive personalities, and — at least for female red junglefowl —optimism, can affect contest initiation and outcome. Therefore, within species, and depending on sex, different aspects of behavior and cognition may independently affect contest initiation and outcome. The generality of these findings, and their fitness consequences, requires further investigation.
\end{abstract}

\section{Significance statement}

In red junglefowl, we explored how behavior previously shown to describe personality, cognition, and affective state affected initiation and outcome of intra-sexual contests, by staging contests between sexually mature individuals previously assayed in behavioral and cognitive tests. In both sexes, contest initiators usually won. Bolder males were more likely to initiate and win contests. Female contests initiators were less active, more aggressive, and less optimistic. Our results suggest that personality and cognition could affect the initiation and outcome of contests and that how this occurs may differ between sexes.

Keywords Animal cognition $\cdot$ Animal personality $\cdot$ Contests $\cdot$ Gallus gallus $\cdot$ Intra-sexual selection

Communicated by K. v. Oers

Electronic supplementary material The online version of this article (https://doi.org/10.1007/s00265-019-2762-0) contains supplementary material, which is available to authorized users.

Hanne Løvlie

hanne.lovlie@liu.se

1 Department of Physics, Chemistry and Biology, IFM Biology, Linköping University, SE-581 83 Linköping, Sweden

2 Faculty of Life Sciences, University of Manchester, M13 9LP, Manchester, UK

3 Department of Animal Environment and Health, Swedish University of Agricultural Sciences, SE-750 07 Uppsala, Sweden

\section{Introduction}

Intra-sexual contests are prevalent in the animal kingdom, and contest winners enjoy increased access to resources, either directly or indirectly by obtaining a higher social status (Andersson 1994; Elwood and Arnott 2012). Morphological differences sometimes, but not always, predict the outcome of such contests (e.g., Andersson 1994; Briffa and Hardy 2013; Chichinadze et al. 2014). Theoretically, differences in personality (i.e., individual differences in behavior that are consistent across time and/or context, Dall et al. 2004) and cognition (i.e., how individuals perceive, store, and act on information from environmental stimuli; Shettleworth 2010) can also 
predict the outcome of contests (Briffa et al. 2015; Reichert and Quinn 2017; Wascher et al. 2018). Understanding the potential fitness consequences of individual variation is crucial for understanding how this variation may evolve. However, studies investigating this (e.g., Hübner et al. 2018) are rare. By affecting access to resources, contest outcomes could affect fitness. Nevertheless, the role of personality and, especially, cognition, in determining the outcome of intrasexual contests is currently unclear.

Individuals performing more proactive behavior (i.e., acting more active, explorative, aggressive, bold, and/or less fearful than their reactive counterparts, Koolhaas et al. 1999; Sih et al. 2004) often win contests (e.g., Dahlbom et al. 2011; David et al. 2011; Favati et al. 2014a), yet it is unclear why this is. As contests are often won by their initiators (e.g., Bekoff and Scott 1989; Jackson 1991; Kar et al. 2016), more proactive individuals may, theoretically, win contests by initiating them. To our knowledge, this has not yet been investigated. For example, more proactive individuals may be more likely to initiate contests because, by behaving more exploratively, they may encounter more opportunities to do so, or, by behaving more boldly, may be more willing to take risks associated with contests (Bornovalova et al. 2009; Briffa et al. 2015). Nevertheless, proactive individuals do not always win contests; some studies show no effect of personality on contest outcome (e.g., Devost et al. 2016; Buwalda et al. 2017), or more reactive individuals to win (e.g., Korzan et al. 2006; Fox et al. 2009). Together, this suggests that the role of personality in determining contest outcome, and, thus, whether certain personalities are more likely to win contests, is not yet fully understood.

Several studies have shown a link between social status and cognition (reviewed in Wascher et al. 2018). For example, faster discriminative learning, better spatial learning and memory, and slower reversal learning have been associated with dominant social status (e.g., Bunnell et al. 1980; Pravusodov et al. 2003; Spritzer et al. 2004; Boogert et al. 2006; Francia et al. 2006; Kar et al. 2017; Langley et al. 2018). However, other studies contradict this; for example, faster reversal learning has also been linked to dominant status (Keynan et al. 2016). Moreover, it is unclear whether the link between cognition and status is due to cognition influencing status (i.e., "prior attributes" hypothesis, Chase et al. 2002), or status influencing cognition (i.e., "social state dependent": hypothesis, Langley et al. 2018). To determine this, cognition needs to be measured before contests for status occur, and such studies are rare (Chichinadze et al. 2014; Wascher et al. 2018). The small number of studies that have done this show that, for example, spatial learning may not predict contest outcome, while lower overall cognitive performance can be associated with winning contests (Barnard and Luo 2002; Cole and Quinn 2012; Matzel et al. 2017). The role of cognition in contests thus warrants further investigation.
Personality and cognition can co-vary and may influence each other (e.g., Zidar et al. 2017b, 2018b, 2019; reviewed in Guillette et al. 2017; Dougherty and Guillette 2018; Sih \& Del Giudice 2012). Therefore, an apparent effect of cognition in contests could be a result from the influence of personality. Thus, individuals that win or lose contests may differ in cognitive traits, even if the cognitive traits do not directly affect contest outcome. Alternatively, cognition may directly affect contest outcome, for example, by driving contest initiation. We investigate this for discriminative learning, impulsivity, and optimism. We hypothesize that being better at discriminative learning, having higher impulsivity (i.e., more likely to respond quickly and without consideration, Hareiman 1947), and being more optimistic (i.e., more likely to overestimate the chances of their actions having a positive outcome, Scheier and Carver 1985) may provide an advantage in contests by driving contest initiation. Better discriminative learning ability may result in contest initiation if it aids the learning of the association between initiating and winning contests. Higher impulsivity could result in contest initiation if it decreases response time, and time spent considering potential risks, when the opportunity to initiate a contest arises. Finally, higher optimism could make individuals overconfident about their chances of winning (e.g., Hey 1984; Bergen 2011) which may drive them to initiate contests, and also, potentially, improve their chances of winning (Johnson and Fowler 2011). While optimism is itself a cognitive bias (Bateson 2016), it is connected to affective state in that a more positive affective state is often linked to higher optimism both in humans (e.g., Nygren et al. 1996; Waters 2008) and other animals (e.g., Brydges et al. 2011; Douglas et al 2012; Asher et al. 2016). Thus, by influencing how optimistic an individual behaves and how it acts in response to a possible contest, an individual's affective state could affect their propensity to initiate and, possibly, win contests. In addition, behaving more proactively is often associated with higher optimism (Sih et al. 2004; Uskul and Greenglass 2005; Asher et al. 2016), suggesting a link between personality and affective state. Thus, both personality, cognition and affective state, may directly and indirectly explain why individuals win contests.

To investigate how behaving in a more proactive manner, as well as aspects of cognition and affective state may influence the initiation and outcome of contests, we exposed sexually mature male and female red junglefowl (Gallus gallus) to a battery of behavioral assays (novel object-, novel arena-, tonic immobility-, and restrained intruder test) and cognitive tests (discriminative learning-, detour reaching-, and cognitive judgement bias tests) before staging intra-sexual contests between morphologically matched individuals. Red junglefowl live naturally in social groups of 2-15 individuals (reviewed in Garnham and Løvlie 2018), in which males and females form separate social hierarchies through intra-sexual contests (Banks 1956; Guhl 1968). Initiators of contests often win 
them (Ligon et al. 1990; Favati et al. 2014a), which result in higher social positions and increased access to resources (e.g., food, mating partners, Collias et al. 1994). Based on previous studies, we predicted that behavior describing more proactive individuals, (showing higher aggression, activity, boldness, exploration, and lower fear), and also aspects describing variation in cognition (such as discriminative learning speed, impulsivity, and optimism), to be positively correlated with initiating and winning these intra-sexual contests.

\section{Methods}

\section{Animals and housing}

In November and December 2016, we used red junglefowl (nmales $=40$, nfemales $=44$ ) from a captive, pedigree-bred, population (housed at Linköping University, Sweden), previous generations of which were used for earlier personality and cognitive studies (e.g., Favati et al. 2016; Zidar et al. 2017a, 2017b; Sorato et al. 2018). These birds took part in the study between 27 and 31 weeks of age (i.e., when sexually mature). Birds were marked, as chicks, with numbered wing tags (Jiffy wing-bands from the National Band and Tag Company). For all tests bar the staged contests (see below), we housed birds in two single sex enclosures $\left(6 \mathrm{~m}^{3}\right)$ with perches, shelters, substrate for dust bathing, and access to an enclosed outdoor area $(250 \times 260 \times 400 \mathrm{~cm}, \mathrm{H} \times \mathrm{W} \times \mathrm{L})$. Commercial poultry food and water was available ad libitum. For 5 days prior to, and during the staged contests, we housed birds in male-female pairs in smaller enclosures $(50 \times 45 \times 60 \mathrm{~cm}, \mathrm{H} \times \mathrm{W} \times \mathrm{L})$ containing a perch, a shelter, substrate for dust bathing, and a laying/brooding area. This was done to standardize the social environment of all birds prior to contests to prevent earlier encounters between birds affecting the outcome of these (Cloutier et al. 1995; Favati et al. 2014a). Because we housed birds with companions of the opposite sex, and staged contests between individuals of the same sex, birds never contested with the individual they were housed with while the staged contests were taking place.

\section{Behavioral test battery}

Between 27 and 29 weeks of age, birds individually took part in a series of behavioral and cognitive tests (see below) to obtain measures of behavior and cognition. Previous studies have shown the behavioral measures taken from these tests to be repeatable in fowl, that is, to be describing variation in personality (Favati et al. 2014a, 2014b, 2016, 2017; Zidar et al. 2017a). The repeatability of the cognitive measures is currently unknown (but see Cauchoix et al. 2018). For all tests, the observer removed the focal bird from its home pen by first dimming the lights, before catching it and bringing it to the test arena. Birds had previously been habituated to handling and the presence of humans, and we did not observe any behavioral signs of stress after this handling (e.g., attempts to escape, distress calls). To minimize observer bias, information on a bird's performance in previous tests was unknown to the observer when behavioral data were recorded.

\section{Novel arena and novel object tests}

To measure activity, exploration and boldness, birds took part in a novel arena test followed immediately by a novel object test ( sensu Zidar et al. 2017a, 2017b). The tests were conducted in an arena $\left(2 \mathrm{~m}^{3}\right)$ which contained peat as substra,te and empty food and water bells to encourage exploration and divide the arena into four equal squares. We conducted the novel arena test for $10 \mathrm{~min}$ after the bird was placed in the arena. After completion of the novel arena test, we placed a novel object (a stuffed toy, ca $10 \mathrm{~cm} \varnothing+10 \mathrm{~cm}$ tail) in the opposite diagonal corner of the arena from where the bird was positioned. Response to a novel object can be affected by whether the object is perceived as attractive or aversive (Greggor et al. 2015), which could make interpretation of behavior in the novel object test difficult. Therefore, we used a novel object with large, potentially frightening, eyes that we assumed to be aversive to our birds. We turned the lights off while adding the novel object to the arena to prevent the bird from seeing and beginning to respond to the novel object before the novel object test began. The novel object test was then conducted for $10 \mathrm{~min}$. Both the novel arena and novel object test were filmed, and behavioral measures were obtained from these videos. In the novel arena and novel object test, we measured activity as the number of times birds moved between the squares (i.e., sub-areas) of the arena (a bird was said to have entered a square when it placed a foot into that square) and boldness as latency to first movement (i.e., first step). In the novel arena test, we also measured exploration as how many different squares the bird visited during the test (ranging from a minimum of 1 square to a maximum of 4 squares). We did not measure exploration in the novel object test as this is recommended to be measured in a previously unexperienced environment (Réale et al. 2010).

\section{Tonic immobility test}

To test fearfulness, we used a tonic immobility test (Forkman et al. 2007; Bertin et al. 2008). The observer placed the bird on its back in a cradle and gently held it down with one hand over the chest and the other hand over the head. After $15 \mathrm{~s}$, the observer slowly lifted their hands and, if the bird remained on its back for at least $3 \mathrm{~s}$, tonic immobility was considered induced. A maximum of 3 attempts to induce tonic immobility were made. Fearfulness was measured as the time (in seconds) the bird spent in tonic immobility, a longer latency indicated 
greater fear (Gallup Jr 1979; Jones 1986). Birds in which tonic immobility could not be induced were given a latency of 0 seconds. Birds that did not come out of tonic immobility within $600 \mathrm{~s}$ were given a latency of $600 \mathrm{~s}$. To prevent any effect of differences in handing, and to minimize human influence, the same observer tested all birds and avoided eye contact with them during the test.

\section{Restrained intruder test}

To obtain a measure of aggression towards, but not influenced by, a conspecific, we used a restrained intruder test (sensu Favati et al. 2014a, 2017). The arena used was the same as used in the novel object and novel arena test. To ensure that the bird was comfortable in the arena, after placing the bird in the arena, we waited until they began foraging/dust bathing (which never took more than $5 \mathrm{~min}$ ) before beginning the test. Once the focal bird was comfortable, we presented them with an intruder restrained in the hands of the test person. We morphologically matched individuals for this test: intruder and focal bird were chosen so that they had a comb length ( $\mathrm{mm}$ ) and weigh $(\mathrm{g})$ within $10 \%$ of each other. This was done to prevent differences in morphology from influencing the focal bird's response. In 53 tests (of 84) an intruder that previously had been used, was used again (maximum 3 times per intruder, and with $\geq 1 \mathrm{hr}$ break in between). In addition, none of the focal birds the intruder faced were used as their intruder when they were the focal bird. We gave the focal bird a maximum of $60 \mathrm{~s}$ in which to respond to the intruder and scored their maximum level of aggression towards the intruder on a scale of 0 8 (higher scores refer to higher aggression, Table 1), an extended version of the scales previously used to score aggression in fowl (Favati et al. 2014a, 2017).

Table 1 Scores used to measure aggression in male and female red junglefowl

Score Description of behavioral response

0 Walk away, or behave fearfully

1 Show only neutral behavior towards opponent, or ignore opponent

2 Take a slight aggressive posture, such as tilted body

3 Take an aggressive posture, e.g., crouch, hackles up, wing drop

4 Make an aggressive motion, e.g., aggressive ground peck, waltz

5 Start an attack, but stop when further away than $60 \mathrm{~cm} / 2$ body lengths

6 Make an aggressive posture/motion and attack within 11-60 s

7 Make an aggressive posture/motion and attack within $10 \mathrm{~s}$

8 Immediately attack

How aggression was scored in the restrained intruded test, based on previous studies on contest behavior of fowl (Kruijt 1964; Favati et al. 2014a, 2017)

\section{Discriminative learning}

To measure learning speed, we used a discriminative learning test, in which birds learnt to associate novel white and black cues with a food reward and a lack of reward, respectively. Each cue used in this test consisted of a bowl $(5 \times 3 \mathrm{~cm}, \varnothing \times$ $\mathrm{H})$ placed against the far wall of an arena $(50 \times 90 \times 60 \mathrm{~cm}, \mathrm{~W}$ $\times \mathrm{L} \times \mathrm{H})$, with a laminated card $\left(9 \mathrm{~cm}^{2}\right)$ of matching color between the bowl and the arena wall. We exposed birds to a series of trials in which one white and one black cue were presented simultaneously with an opaque divider between them. A trial started when the bird was placed in the arena, at the opposite end of the arena to where the cues were positioned, and ended either when the bird left the arena, or chose a cue. We considered birds to have chosen a cue when they approached it without help and had their head within $2 \mathrm{~cm}$ of it. To prevent birds developing side preferences, we presented the rewarded (i.e., black) and unrewarded (i.e., white) cues on different sides according to a predetermined, pseudorandom schedule. Birds were removed from the arena between trials. We measured speed to learn the discrimination (hereafter termed "learning speed") as the number of trials the bird had before it chose the correct cue in six consecutive trials (Sorato et al. 2018; Zidar et al. 2018b, 2019). Due to an apparent lack of motivation towards food rewards in males, only females completed this test (see also Zidar et al. 2018b). Therefore, whether discriminative learning affected contest initiation or outcome was only investigated in females.

\section{Detour reaching test}

To measure impulsivity, we used a detour reaching test (MacLean et al. 2014; Shaw et al. 2015). Prior to testing, to familiarize the birds to transparent barriers, we trained them to navigate around a three-walled Plexiglas structure $(13 \times 13 \times$ $20 \mathrm{~cm}, \mathrm{~W} \times \mathrm{L} \times \mathrm{H}$ ) to gain food rewards (mealworms). Once they did this three consecutive times, without attempting to walk through the Plexiglas, we considered this familiarization complete. We then trained the birds the detour to use to obtain a reward from the center of a tube. To do so, we placed a reward in the center of an opaque tube $(7 \varnothing \times 8 \mathrm{~L} \mathrm{~cm})$, placed on its side, and encouraged the birds to approach and look into this. Encouragement was either by placing other rewards near the end of the tube or tapping on the tube with tweezers (an action which our birds had learned signals the presence of a reward). We considered birds to have learned the detour once they retrieved the reward five consecutive times from the center of the opaque tube without needing encouragement to do so or pecking the tube, by putting their head in the open end of the tube. In the test, we presented the birds with a transparent tube $(7 \varnothing \times 8 \mathrm{~L} \mathrm{~cm})$ with a reward inside. At the start of the test, the bird was positioned at one of the short ends of the arena (the same arena as used in the discriminative learning test) 
facing the tube which was placed at the opposite side of the arena from them such that they faced the side of the tube. We measured impulsivity as the number of times, out of a total of five, the bird pecked directly at the food reward through the transparent surface of the tube rather than using the previously learnt detour to obtain the reward (a higher number indicated higher impulsivity, MacLean et al. 2014; Shaw et al. 2015).

\section{Judgement bias test}

To assess affective state and optimism, we conducted a judgement bias test (Harding et al. 2004). In this test, we presented the birds with five different cues, one at a time, in a pseudo-random order (Sorato et al. 2018; Zidar et al. 2018a). These cues again consisted of a bowl $(5 \times 3 \mathrm{~cm}, \varnothing \times \mathrm{H})$ and a laminated card $(9$ $\mathrm{cm}^{2}$ ) in matching colors. Birds were presented with the previously learned rewarded white cue eight times, the black unrewarded cue seven times, and three novel, ambiguous, unrewarded cues, intermediate between black and white ("light grey" 75\% white/25\%black; "mid grey" 50\%white/50\%black; "dark grey" $25 \%$ white $75 \%$ black) two times each. As this test required birds to have passed the discriminative learning test, only females participated in it. To obtain a measure of a bird's optimism towards ambiguous cues, we recorded their average latency (in seconds) to approach each of these cues; a shorter latency indicated higher optimism and a more positive affective state (Mendl et al. 2010; Sorato et al. 2018; Zidar et al. 2018a). Birds were given a maximum latency of $60 \mathrm{~s}$ if they did not approach within $60 \mathrm{~s}$.

\section{Staged duels}

At 31 weeks old, birds $\left(n_{\text {male pairs }}=20, n_{\text {female pairs }}=22\right)$ took part in staged intra-sexual contests (sensu Favati et al. 2014a) to determine whether the behavior and cognitive measures obtained could predict the initiators and winners of contests. The arena used was familiar to all birds (the arena used in the novel arena and novel object tests). We matched contesting pairs in terms of morphology, again to reduce its effect on contest outcome (sensu Favati et al. 2014a). Pairs were mismatched in terms of impulsivity, but no other measures determined chosen contestants. The pairs used in these duels were not familiar to each other from the restrained intruder tests. We recorded the initiators and winners of the contest by first-hand observation. The initiator was the bird that performed the first offensive aggressive action towards their opponent; a bird won the contest when their opponent avoided their approach three consecutive times. Previous studies on contests in fowl by our group (e.g., Favati et al. 2014a, 2017) used five consecutive times; however, as reversals in status were never observed after three times, fewer interactions were here used, making data collection more efficient. Apart from one contest which resulted in a draw as the males involved did not contest (these males were excluded from later analysis), there was always a clear winner and loser within each pair. These contests were carefully watched, the observer could quickly separate the birds if necessary, and veterinary care was available if it had been needed. However, physical interactions did not last longer than $15 \mathrm{~s}$ at most and did not escalate or result in injuries, besides some minor bleeding from their combs.

\section{Statistical analyses}

\section{We used R version 3.5.2 ( $\mathrm{R}$ core team 2019) for analysis.}

Initially to investigate relationships between our measures and with the aim to reduce the number of variables in our model, we ran a PCA on our behavioral, cognitive, and morphological measures. However, this did not reduce the measures into components that were easy to interpret (data not shown); hence, we ran analyses on our raw data. To further investigate potential links between our behavioral and cognitive measures, we calculated Spearman's rank correlations between them and, when measures were strongly correlated $\left(r_{s}> \pm\right.$ 0.5 ), we did not include both measures in the same model. To further avoid any multicollinearity, if any variable of the global model (see below) had a variance inflation factor (VIF) under 4 , the model was remade continuously taking out one variable at a time, starting with the one that predicted the response variable the least when modeled alone, until the VIF for all variables in the model was under 4.

To determine what best predicted contest initiation and outcome in males and females, we used binary generalized linear mixed models constructed in the "lme4" package (Bates et al. 2015), with a binomial distribution. In these separate models, "initiation" (yes, no) or "outcome" (winner, loser) were the response variables, and our behavioral, cognitive, and morphological measures the predictor variables. To determine the best predictors, we performed model selection using the "MuMIn" package and the function "dredge" (Barton 2019). Due to expected sex differences in the dimorphic red junglefowl, we modeled each sex separately.

For optimism, only one measure was used (latency to approach the mid grey cue), as this was strongly correlated with latency to approach a light grey cue and latency to approach a dark grey cue (light grey: $r_{s}=0.61, N=22, p<0.01$; dark grey: $\left.r_{s}=0.69, N=22, p<0.01\right)$.

We ranked the models according to AICc (AIC values adjusted for small sample sizes; lower values indicate a better goodness of fit). To estimate the most parsimonious models (hereafter termed "best model"), we used the conventional cutoff point of $\triangle \mathrm{AICc}<2$. For comparison, we included and compared these to a "null model" containing only the intercept. To evaluate relative support for the best models, we used AICc $\omega$, and to evaluate the relative support for the individual variables, we used the sum of AICc $\omega$ ( $\Sigma \mathrm{AICc} \omega)$. 
Predictor variables that had a $\Sigma$ AICc $\omega$ of 1 were considered "significant".

\section{Results}

In males, the global model for contests initiation included all behavioral, cognitive, and morphological measures we had collected. In the best models for contest initiation in males, latency to move in the novel arena test was a significant predictor (male initiators had a shorter latency: $z=1.27$, estimate $=-0.03$, note that $z$ scores and estimates given throughout the results are averaged over the best models, Tables 2 and 3, Fig. $1)$. The best models of male initiation better explained variation in our data, compared with the null model $(\Delta \mathrm{AICc}>>2$, Table 2).

For contest outcome in males, the global model included all behavioral, cognitive, and morphological measures taken, bar initiation, which needed to be removed from the global model to avoid multicollinearity. When tested alone, initiation strongly predicted contest outcome (male initiators usually won: $z=3.89$, estimate $=5.67$ ). In the best models for male contest outcome, latency to move in the novel arena test was a significant predictor (male initiators had a shorter latency: $z=$ 1.23, estimate $=-0.04$, Tables 2 and 3, Fig. 1). The best models of contest outcome in males better explained variation in our data than the null model ( $\triangle \mathrm{AICc}>>2$, Table 2$)$.

In females, the global model for contest initiation included all behavioral, cognitive, and morphological measures taken. The variables that significantly predicted female contest initiation in the best models were activity in the novel object test (female initiators were less active: $z=1.94$, estimate $=-0.08$ ), aggression (female initiators were more aggressive: $z=2.26$, estimate $=0.45$ ), and optimism (female initiators were less optimistic: $z=2.14$, estimate $=0.05$, Tables 2 and 3, Fig. 2). The best models of female initiation were better than the null model ( $\triangle \mathrm{AICc}>>2$, Table 2$)$.

For female contest outcome, the global model included all behavioral, cognitive, and morphological variables bar impulsivity, which needed to be removed from the global model to avoid multicollinearity. Impulsivity did not affect the outcome of contests in females $(z=0.17$, estimate $=0.30)$. The variable that significantly predicted female contest outcome in the best models was initiation (female initiators usually won: $z=3.67$, estimate $=3.85$, Tables 2 and 3$)$. The best models were better than the null model ( $\triangle \mathrm{AICc}>>2$, Table 2, Fig. 2).

\section{Discussion}

We show that, for both sexes of red junglefowl, contests were more likely to be won by their initiators. Further, for males, how boldly they behaved in a novel arena predicted both contest initiation and outcome. On the other hand, females that initiated contests scored higher in our measure of aggression, and, against our predictions, were less active in a novel object test and scored lower in our measure of optimism. Overall, our results suggest that behavior used to describe personality, cognition, or affective state can play a role in the initiation and outcome of contests, and that this may differ between the sexes.

Making conclusions based on the effects of individual variation in a trait when using single measures can be problematic (e.g., Beckmann and Biro 2013; Niemelä and Dingemanse 2018). We only took each behavioral and cognitive measure once per individual, meaning that our findings are at a phenotypic, rather than individual level. However, if individuals are consistent in these traits, which previously has been the case in fowl for our behavioral measures obtained in personality assays (Favati et al. 2014a, 2014b, 2016, 2017; Zidar et al. 2017 a), our results can indicate how differences in personality and cognition can affect future social status. We suggest that future investigation of the effect of personality or cognition on contests could use a multivariate approach, measuring traits of interest at different times or in different contexts.

In males, boldness (measured as latency to move in the novel arena test), was associated with initiating and winning contests. Higher levels of boldness could cause individuals to initiate and win contests by making them more willing to take the risks needed to do so (Briffa et al. 2015). Latency to move in a novel arena test was not correlated with latency to move in the novel object test (our other measure of boldness) suggesting that these might capture different aspects of boldness and that only certain aspects may influence contest outcome. The large eyes of our novel object could potentially have mimicked a predator, thus may reflects boldness in the presence of a perceived threat, whereas response in the novel arena test could reflect boldness where no direct threat is perceived. Unlike previous studies on fowl (e.g., Ligon et al. 1990; Favati et al. 2014a, 2017), we did not find more aggressive males more likely to win contests. In our males, comb size was significantly correlated with aggression $\left(r_{s}=-0.45, p<0.01\right)$. Therefore, if our males were consistent in how aggressive they were (as in Favati et al. 2014a, 2017), matching males for comb size might have reduced variation in aggression enough that it could no longer influence the contests. Furthermore, our measures of boldness and aggression did not correlate (dissimilar to other species, e.g., Huntingford 1976; Riechert and Hedrick 1993; van Oers et al. 2005; be Sih \& Bell 2008) and, thus, including both these measures in our model selection should not have caused issues with correlation or multicollinearity. Overall, our findings support previous work on male fowl which found that several independent aspects of behavior can predict future social 
Table 2 Models explaining contest initiation and outcome in sexually mature female and male red junglefowl

\begin{tabular}{|c|c|c|c|c|c|}
\hline Model & Rank & Estimate & $\mathrm{AICc}$ & $\Delta \mathrm{AICc}$ & AICcw \\
\hline \multicolumn{6}{|l|}{ (i) Contest initiation in females } \\
\hline Act $\mathrm{NO}+\mathrm{Agg}+\mathrm{Lat} \mathrm{TI}+\mathrm{Opt}$ & 1 & $-0.08|0.49|-0.00 \mid 0.06$ & 50.0 & 0 & 0.33 \\
\hline $\mathrm{Act} \mathrm{NO}+\mathrm{Agg}+\mathrm{Opt}$ & 2 & $-0.08|0.38| 0.04$ & 50.3 & 0.33 & 0.28 \\
\hline Act $\mathrm{NO}+\mathrm{Agg}+\mathrm{Lat} \mathrm{TI}+\mathrm{Opt}+\operatorname{Exp}$ & 3 & -0.08||$-0.63|-0.01| 0.07 \mid 0.52$ & 50.5 & 0.51 & 0.27 \\
\hline $\mathrm{Act} \mathrm{NO}+\mathrm{Agg}+\mathrm{Opt}+\mathrm{Comb}$ & 4 & $-0.08|0.39| 0.05 \mid-0.11$ & 51.8 & 0.51 & 0.13 \\
\hline Null model & 747 & & 60.2 & 10.24 & 0 \\
\hline \multicolumn{6}{|l|}{ (ii) Contest outcome in females (without impulsivity) } \\
\hline Initiate & 1 & 4.04 & 34.8 & 0 & 0.25 \\
\hline Initiate + Opt & 2 & $3.93 \mid+0.03$ & 35.2 & 0.37 & 0.21 \\
\hline Initiate + Agg & 3 & $3.80 \mid 0.30$ & 35.3 & 0.49 & 0.20 \\
\hline Initiate $+\mathrm{Opt}+\mathrm{Agg}$ & 4 & $3.63|0.03| 0.28$ & 35.9 & 1.04 & 0.15 \\
\hline Initiate + Learning & 5 & $3.97 \mid 0.02$ & 36.6 & 1.79 & 0.10 \\
\hline Initiate + Opt + Agg + Lat TI & 6 & $3.55|0.06| 0.43 \mid-0.00$ & 36.8 & 1.97 & 0.09 \\
\hline Null model & 2564 & & 60.3 & 25.49 & 0 \\
\hline \multicolumn{6}{|l|}{ (iii) Contest initiation in males } \\
\hline Agg + Lat NA + Lat NO & 1 & $-0.47|-0.04|-0.02$ & 46.1 & 0 & 0.22 \\
\hline Lat NA + Act NO & 2 & $-0.02 \mid 0.03$ & 46.8 & 0.63 & 0.16 \\
\hline Lat NA & 3 & -0.02 & 47 & 0.89 & 0.14 \\
\hline Agg + Lat NA + Lat NO + Weight & 4 & $-0.59|-0.05|-0.02 \mid-0.01$ & 47 & 0.91 & 0.14 \\
\hline Lat NA + Lat NO & 5 & $-0.02 \mid 0.01$ & 47.1 & 0.98 & 0.13 \\
\hline Agg + Lat NA + Lat $\mathrm{NO}+$ Act $\mathrm{NO}$ & 6 & $-0.46|0.04|-0.01 \mid 0.03$ & 47.3 & 1.21 & 0.12 \\
\hline Lat NA + Lat NO + Act NO & 7 & $-0.02|-0.01| 0.03$ & 47.8 & 1.65 & 0.10 \\
\hline Null model & 107 & & 52 & 5.89 & 0.00 \\
\hline \multicolumn{6}{|l|}{ (iv) Contest outcome in males (without initiation) } \\
\hline Act NA + Agg + Lat NA + Lat NO & 1 & $0.76|-0.66|-0.06 \mid-0.02$ & 45.1 & 0 & 0.18 \\
\hline Agg + Lat NA + Lat NO & 2 & $-0.50|-0.06| 0.01$ & 42.2 & 0.11 & 0.17 \\
\hline Act $\mathrm{NA}+$ Agg + Lat NA + Lat $\mathrm{NO}+$ Act $\mathrm{NO}$ & 3 & $1.05|-0.71|-0.05|-0.02| 0.04$ & 45.6 & 0.55 & 0.14 \\
\hline Lat NA & 4 & -0.03 & 46.0 & 0.93 & 0.11 \\
\hline Lat NA + Lat NO & 5 & $-0.04 \mid-0.01$ & 46.4 & 1.35 & 0.09 \\
\hline Lat NA + Act NO & 6 & $0.02 \mid-0.03$ & 46.5 & 1.45 & 0.09 \\
\hline Act $\mathrm{NA}+$ Act $\mathrm{NO}+$ Lat NA & 7 & $0.68|0.03|-0.02$ & 46.6 & 1.51 & 0.08 \\
\hline Act NA + Lat NA & 8 & $-0.02 \mid 0.5$ & 46.8 & 1.76 & 0.07 \\
\hline Agg + Lat NA + Lat $\mathrm{NO}+$ Act $\mathrm{NO}$ & 9 & $-0.49|-0.05|-0.01|0.02|$ & 46.9 & 1.89 & 0.07 \\
\hline Null model & 157 & & 52 & 6.97 & 0.00 \\
\hline
\end{tabular}

Initiation and outcome are binary (initiation: yes $=1$, no $=0$; outcome: won $=1$, lost $=0$ ). Models are ranked according to their AICc value and weight (AICc $\omega$ ). Models shown are those within $\triangle \mathrm{AICc}<2$, and the "Null model" model, for comparison. Estimates for all supported variables are given separated by a $\mid$ and in the same order as variables appear in the model column

Act NA activity in a novel arena test (NA), Act NO activity in novel object test (NO), Agg aggression towards a restrained opponent (0-8), Exp latency (sec) to explore NA, Lat NA latency to first step (sec) in NA, Lat NO latency to first step (sec) in NO, Lat TI latency to righten (sec) in a tonic immobility test, Opt latency to approach a grey cue (sec) in judgement bias test, Learning number of trials until six correct choices in a discriminative learning test, Weight body weight in grams, Comb length of comb (mm)

status (Favati et al. 2014a), including aspects describing boldness.

In females, those that initiated contests were more aggressive in a restrained intruder test, and, against our predictions, less active in a novel object test, and less optimistic in a cognitive judgement bias test. Aggression is, therefore, important for contest initiation not only in male
(Favati et al. 2014a) but also in female fowl. Lower levels of activity may indicate higher fearfulness (Forkman et al. 2007), for example, if fearfulness results in behavioral inhibition (Jones 1996; Mills et al. 1997). Alternatively, if positively correlated with escape attempts for example (Budaev 1998; Andersen et al. 2008), lower levels of activity could indicate lower levels of fearfulness. Due to 
Table 3 Overview of importance of variables from the selected models explaining contest initiation and outcome among sexually mature male and female red junglefowl

\begin{tabular}{lc}
\hline Model & EAICcw \\
\hline (i) Contest initiation in females & \\
Activity NO & 1 \\
Aggression & 1 \\
Optimism & 1 \\
Latency TI & 0.59 \\
Exploration & 0.26 \\
Comb size & 0.13 \\
(ii) Contest outcome in female (without impulsivity) \\
Initiation & 1 \\
Optimism & 0.45 \\
Aggression & 0.44 \\
Learning & 0.1 \\
Latency TI & 0.09 \\
(iii) Contest initiation in males & \\
Latency NA & 1 \\
Latency NO & 0.7 \\
Aggression & 0.47 \\
Activity NO & 0.37 \\
Weight & 0.14 \\
(iv) Contest outcome in males (without initiation) \\
Lat NA & 1 \\
Latency NO & 0.64 \\
Aggression & 0.55 \\
Activity NA & 0.47 \\
Activity NO & 0.38 \\
\hline & \\
\hline &
\end{tabular}

$\Sigma$ AICcu indicates the proportion of models the variable features in Activity NA activity in a novel arena test (NA), Activity $N O$ activity in novel object test (NO), Aggression aggression towards a restrained opponent (0-8), Exploration latency (sec) to explore a novel arena, Latency $N A$ latency to first step (sec) in a novel arena, Latency $N O$ latency to first step (sec) in a novel object test, Latency $T I$ latency to righten $(\mathrm{sec})$ in a tonic immobility test, Optimism latency to approach a grey cue (sec) in judgement bias test, Learning number of trials until six correct choices in a discriminative learning test

this, activity in the novel object test can be difficult to interpret, and in our case could include aspects of antipredator responses. Nevertheless, we did not observe a significant link between activity and escape attempts, or latency to righten after induction of tonic immobility $\left(r_{s}<\right.$ $\pm 0.3, N=22, p>0.07)$, suggesting that activity independent of fearfulness explained initiation of contests in our females.

Lower optimism might be linked to contest initiation if it results in the assumption that situations are less likely to end favorably (Scheier and Carver 1985). Thus, less optimistic females might have initiated the contest to try to gain an initial advantage and put greater effort into winning. This explanation,

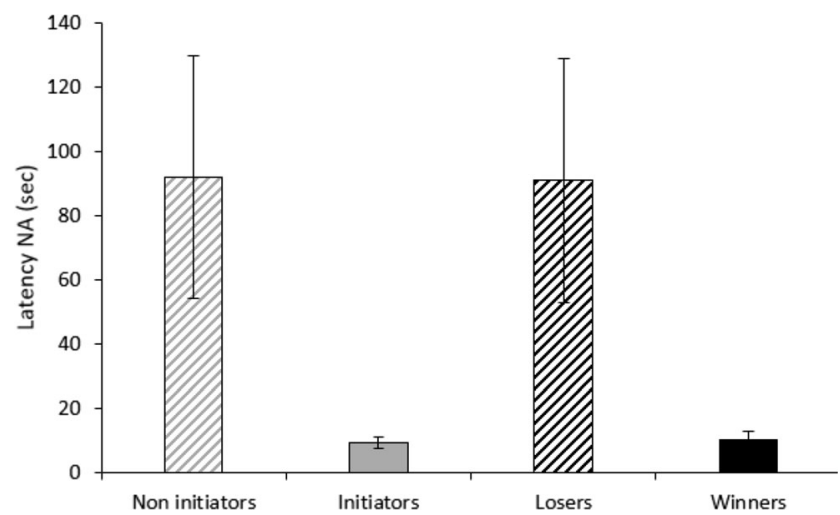

Fig. 1 Comparison of behavioral measures between red junglefowl male non-initiators and initiators. Males that initiated and won contests had a faster latency to move in a novel arena test (Latency NA) than noninitiators and losers. Mean and standard error are given. Striped grey = non-initiators, solid grey $=$ initiators, striped black $=$ losers, solid black $=$ winners. $N=19$ pairs

however, presumes that these females know the association between initiating and winning contests. Initially, we predicted that being better at discriminative learning lead would to initiating contests by aiding the learning of this association. However (like in Sorato et al. 2018), we found no relationship between discriminative learning and optimism. Thus, the aspect of learning measured in our discriminative learning test (i.e., making the correct choice between two options to gain a reward) may not been the type of learning used to form an association between initiating and winning contests. That optimism influenced contest initiation indicates that individuals with a less positive affective state may be more likely to initiate contests; thus, affective state may play a role in contest initiation. Due to the limited work on cognitive variation in female contests, further research is encouraged to explore the generality of our findings.

Activity, aggression, and optimism were all phenotypically independent of each other in our population. Thus, this suggests that behavior and cognition may directly influence contest initiation through several routes. Furthermore, this suggests that the reason for lower optimism being linked to winning contests is not due to a trade-off between optimism and aggression. Only whether females initiated a contest was directly linked to their chance of winning the contest. However, by predicting contest initiation, activity, aggression, and optimism indirectly affected the outcome of contests in females.

Aggression and boldness can, in general, be positively correlated with a more proactive behavioral type, whereas fearfulness can be positively correlated with a more reactive behavioral type (Koolhaas et al. 1999). In addition, more reactive individuals also often have lower optimism (Sih et al. 2004; Uskul and Greenglass 2005; Asher et al. 2016). Thus, while different behavioral and cognitive measures predicted the initiation and/or outcome of contests in males and females, our results mainly agree with 

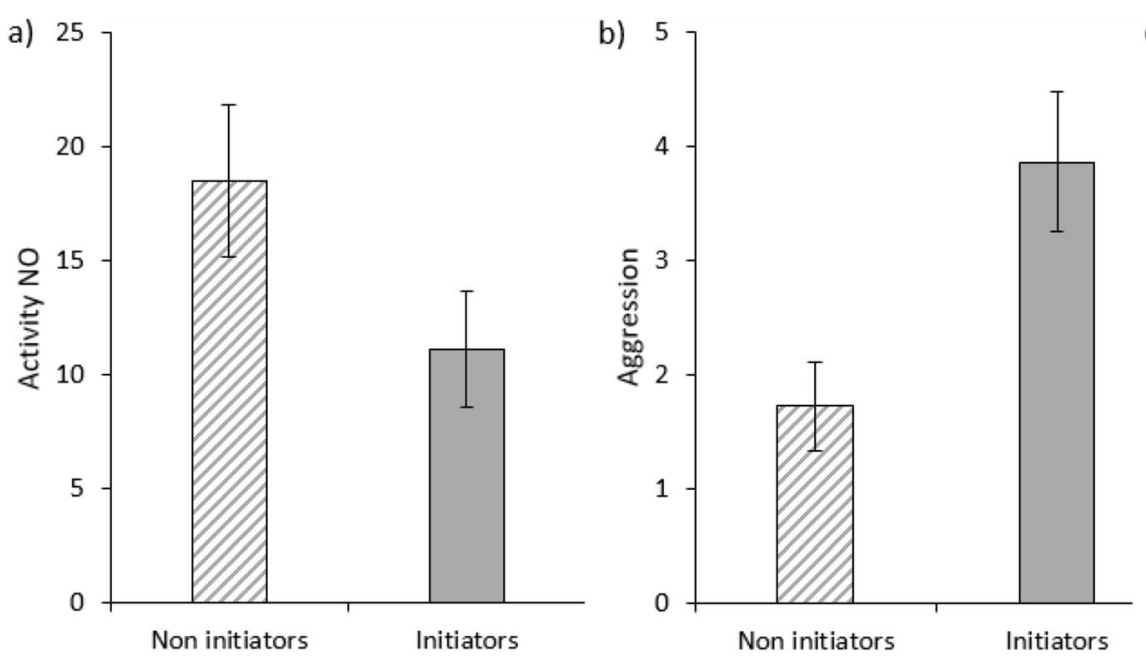

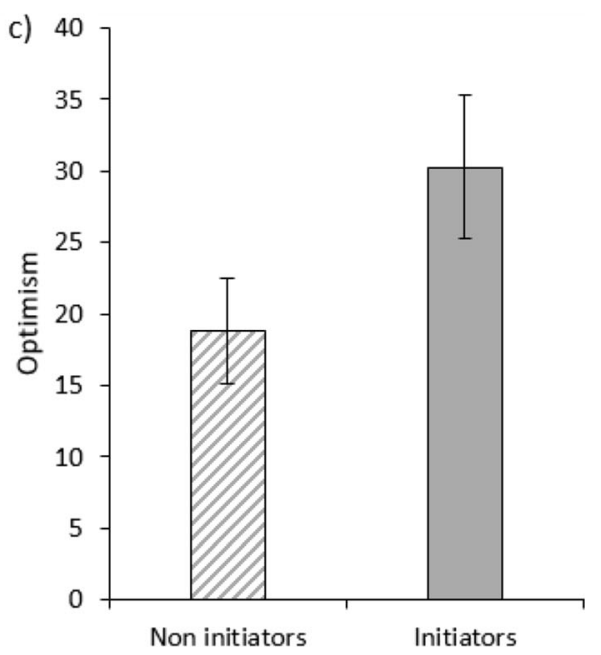

Fig. 2 Comparison of behavioral and cognitive measures between red junglefowl female non-initiators and initiators. Female initiators were less active (a), more aggressive (b), and less optimistic (c), than those that did not initiate contests. Activity $(\mathrm{NO})=$ the number of times a bird

moved between squares during a novel object test. Aggression = scored in a restrained intruder test. Optimism $=$ latency to approach the mid grey cue in the judgement bias test. Mean and standard error are given. Striped grey $=$ non-initiators, solid grey $=$ initiators. $N=22$ pairs

the general pattern in vertebrates that individuals with more proactive behavior usually, but do not always, win contests (Verbeek et al. 1996; Korzan et al. 2006; Dahlbom et al. 2011; David et al. 2011; Favati et al. 2014a; Perry et al. 2017). Our lack of an effect of certain behaviours found to affect contests in other species to explain contest initiation and outcome in fowl suggests their role in contests to be species specific. Overall, both more proactive and more reactive behavior were associated with initiating and winning contest suggesting that more proactive and more reactive individuals may have similar success in contests overall. If this is the case, variation in such behavioral types could be maintained within populations (Koolhaas et al. 1999; Dall et al. 2004; Sih et al. 2004).

The social hierarchies of male and female fowl are structurally similar and both formed through intra-sexual contests (Banks 1956; Guhl 1968; Collias and Collias 1996). Our current results confirm that behavior and cognition may be important in these contests for both sexes. However, our results suggest that their roles in the initiation and outcome of these contests can vary between the sexes. Therefore, future research on animal contests, and particularly regarding the role of behavior or cognition, should consider both sexes. Sex differences in fowl are expected as they are sexually dimorphic and have phenotypic and physiological differences (e.g., sex hormones, Gahr 2001), which can influence both behavior and cognition (Wade 1999; Losecaat Vermeer et al. 2016; Moraga-Amaro et al. 2017). As we were not able to measure discriminative learning speed or optimism in males, we could not explore the extent to which cognition influences contest outcome in both sexes. Overall, the explanation for the different effects of behavior and cognition in contest outcome between males and females warrants further research.

\section{Conclusion}

To conclude, our results suggest that behavior describing both proactive and reactive types can win intra-sexual contests. Variation in behavior and cognition may influence different aspects of a contest: notably likelihood to initiate, and performance during the contest. In addition, the role behavior and cognition may play in contest initiation and outcome may vary depending on sex. Overall, our results suggest that there can be multiple ways that behavior and cognition can affect the initiation and outcome of contests. The generality of these results needs to be explored further, together with their fitness consequences.

Acknowledgments We would like to thank Anna Favati for discussion, Diana Rubene and Killian Martin for help with model selection, Lejla Bectik for animal care, editor Kees van Oers, and 2 anonymous reviewers for useful comments on our manuscript. The work was carried out within the Centre of Excellence in Animal Welfare Science, a collaborative research environment.

Authors' contribution LCG and HL designed the study. SAP, SC, SF, and LCG collected data. LCG analyzed the data in discussion with HL. LCG and HL wrote the paper, and all authors commented on it. HL funded and supervised the study.

Funding information Open access funding provided by Linköping University. Funding was awarded to HL from the Swedish research council Formas. 
Data availability Data collected and analyzed for this study is available as online supplementary material (Table S1, S2).

\section{Compliance with ethical standards}

Competing interests The authors declare that they have no competing interests.

Ethical approval All applicable international, national, and/or institutional guidelines for the care and use of animals were followed. All procedures performed in studies involving animals were in accordance with the ethical standards of the institution or practice at which the studies were conducted (Linköping ethical committee, approved permit with permit number 50-13).

Open Access This article is distributed under the terms of the Creative Commons Attribution 4.0 International License (http:// creativecommons.org/licenses/by/4.0/), which permits unrestricted use, distribution, and reproduction in any medium, provided you give appropriate credit to the original author(s) and the source, provide a link to the Creative Commons license, and indicate if changes were made.

\section{References}

Andersen IL, Roussel S, Ropstad E, Braastad BO, Steinheim G, Janczak GM, Jorgensen GM, Boem KE (2008) Social instability increases aggression in groups of dairy goats, but with minor consequences for the goats' growth, kid production and development. Appl Anim Behav Sci 14:132-148. https://doi.org/10.1016/j.applanim.2008.01. 007

Anderson RC, Searcy WA, Peters S, Hughes M, Du Bois AL, Nowicki S (2017) Song learning and cognitive ability are not consistently related in a songbird. Anim Cogn 20:309-320 https://doi-org.e.bibl. liu.se/10.1007/s10071-016-1053-7

Andersson M (1994) Sexual selection. Princeton University Press, Princeton

Asher L, Friel M, Griffin K, Collins LM (2016) Mood and personality interact to determine cognitive biases in pigs. Biol Lett 12: 20160402. https://doi.org/10.1098/rsbl.2016.0402

Banks EM (1956) Social organization in red jungle fowl hens (Gallus gallus subsp.). Ecology 37:239-248. https://doi.org/10.2307/ 1933136

Barnard CJ, Luo N (2002) Acquisition of dominance status affects maze learning in mice. Behav Process 60:53-59. https://doi.org/10.1016/ S0376-6357(02)00121-3

Barton K (2019) MuMIn: multi-model inference. R package version 1.43.6, https://CRAN.R-project.org/package=MuMIn

Bates D, Maechler M, Bolker B, Walker S (2015) Fitting linear mixedeffects models using lme4. J Stat Softw 67:1-48. https://doi.org/10. 18637/jss.v067.i01

Bateson M (2016) Optimistic and pessimistic biases: a primer for behavioural ecologists. Curr Opin Behav Sci 12:115-121. https://doi.org/ 10.1016/j.cobeha.2016.09.013

Beckmann C, Biro PA (2013) On the validity of a single (boldness) assay in personality research. Ethology 119:937-947. https://doi.org/10. 1111/eth. 12137

Bekoff M, Scott AC (1989) Aggression, dominance, and social organization in evening grosbeaks. Ethology 83:177-194. https://doi.org/ 10.1111/j.1439-0310.1989.tb00528.x

Bertin A, Richard-Yris M, Houdelier C, Lumineau S, Möstl E, Kuchar A, Hirschenhauser K, Kotrschal K (2008) Habituation to humans affects yolk steroid levels and offspring phenotype in quail. Horm Behav 54:396-402. https://doi.org/10.1016/j.yhbeh.2008.04.012

Boogert NJ, Reader SM, Laland KN (2006) The relation between social rank, neophobia and individual learning in starlings. Anim Behav 72:1229-1239. https://doi.org/10.1016/j.anbehav.2006.02.021

Bornovalova MA, Cashman-Rolls A, O'Donnell JM, Ettinger K, Richards JB, de Wit H, Lejuez CW (2009) Risk taking differences on a behavioral task as a function of potential reward/loss magnitude and individual differences in impulsivity and sensation seeking. Pharmacol Biochem Behav 93:258-262. https://doi.org/10.1016/j. pbb.2008.10.023

Briffa M, Hardy ICW (2013) Introduction to animal contests. In: Hardy ICW, Briffa M (eds) Animal Contests. Cambridge University Press, Cambridge, pp 1-4

Briffa M, Sneddon LU, Wilson AJ (2015) Animal personality as a cause and consequence of contest behaviour. Biol Lett 11:20141007. https://doi.org/10.1098/rsbl.2014.1007

Brucks D, Marshall-Pescini S, Wallis L, Huber L, Range F (2017) Measures of dogs' inhibitory control abilities do not correlate across tasks. Front Psychol 8:849. https://doi.org/10.3389/fpsyg.2017. 00849

Brydges M, Leach M, Nicol K, Wright R, Bateson M (2011) Environmental enrichment induces optimistic cognitive bias in rats. Anim Behav 81:169-175. https://doi.org/10.1016/j.anbehav.2010. 09.030

Budaev S (1998) How many dimensions are needed to describe temperament in animals: a factor reanalysis of two data sets. ISCP 11:1729

Bunnell BN, Gore WT, Perkins MN (1980) Performance correlates of social behavior and organization: social rank and reversal learning in crab-eating macaques (M. fascicularis). Primates 21:376-388. https://doi.org/10.1007/BF02373829

Buwalda B, Koolhaas JM, de Boer SF (2017) Trait aggressiveness does not predict social dominance of rats in the Visible Burrow System. Physiol Behav 178:134-143

Cauchoix M, Chow PKY, van Horik JO et al (2018) The repeatability of cognitive performance: a meta-analysis. Philos Trans R Soc B 373: 20170281. https://doi.org/10.1098/rstb.2017.0281

Chase ID, Tovey C, Spangler-Martin D, Manfredonia M (2002) Individual differences versus social dynamics in the formation of animal dominance hierarchies. P Natl Acad Sci USA 99:57445749. https://doi.org/10.1016/j.physbeh.2017.01.008

Chichinadze K, Chichinadze N, Gachechiladze L, Lazarashvili A, Nikolaishvili M (2014) Physical predictors, behavioural/emotional attributes and neurochemical determinants of dominant behaviour. Biol Rev 89:1005-1020. https://doi.org/10.1111/brv.12091

Cloutier S, Beaugrand JP, Laguë PC (1995) The effect of prior victory or defeat in the same site as that of subsequent encounter on the determination of dyadic dominance in the domestic hen. Behav Process 34:293-298. https://doi.org/10.1016/0376-6357(95)00006-G

Cole EF, Quinn JL (2012) Personality and problem-solving performance explain competitive ability in the wild. Proc R Soc Lond B 279: 1168-1175. https://doi.org/10.1098/rspb.2011.1539

Collias NE, Collias EC (1996) Social organization of a red junglefowl, Gallus gallus, population related to evolution theory. Anim Behav 51:1337-1354. https://doi.org/10.1006/anbe.1996.0137

Collias N, Collias E, Jennrich RI (1994) Dominant red junglefowl (Gallus gallus) hens in an unconfined flock rear the most young over their lifetime. Auk 111:863-872. https://doi.org/10.2307/4088818

Dahlbom SJ, Lagman D, Lundstedt-Enkel K, Sundström LF, Winberg S (2011) Boldness predicts social status in zebrafish (Danio rerio). PLoS One 6:e23565. https://doi.org/10.1371/journal.pone.0023565

Dall SRX, Houston AI, McNamara JM (2004) The behavioural ecology of personality: consistent individual differences from an adaptive perspective. Ecol Lett 7:734-739. https://doi.org/10.1111/j.14610248.2004.00618.x 
David M, Auclair Y, Cézilly F (2011) Personality predicts social dominance in female zebra finches, Taeniopygia guttata, in a feeding context. Anim Behav 81:219-224. https://doi.org/10.1016/j. anbehav.2010.10.008

Devost I, Jones TB, Cauchoix M, Montreuil-Spencer C, Morand-Ferron J (2016) Personality does not predict social dominance in wild groups of black-capped chickadees. Anim Behav 122:67-76

Dougherty L, Guillette L (2018) Linking personality and cognition: a meta-analysis. Philos Trans R Soc B 373:20170282. https://doi. org/10.1098/rstb.2017.0282

Douglas C, Bateson M, Walsh C, Bédué A, Edwards SA (2012) Environmental enrichment induces optimistic cognitive biases in pigs. Appl. Anim. Behav. Sci. 139:65-73. https://doi.org/10.1016/ j.applanim.2012.02.018

Elwood RW, Arnott G (2012) Understanding how animals fight with Lloyd Morgan's canon. Anim Behav 84:1095-1102. https:/doi. org/10.1016/j.anbehav.2012.08.035

Evenden JL (1999) Varieties of impulsivity. Psychopharmacology 146: 348-361. https://doi.org/10.1007/pl00005481

Favati A, Leimar O, Løvlie H (2014a) Personality predicts social dominance in male domestic fowl. PLoS One 9:e103535. https://doi.org/ 10.1371/journal.pone. 0103535

Favati A, Leimar O, Radesäter T, Løvlie H (2014b) Social status and personality: stability in social state can promote consistency of behavioural responses. Proc R Soc B 281:2013253. https://doi.org/10. 1098/rspb.2013.2531

Favati A, Zidar J, Thorpe H, Jensen P, Løvlie H (2016) The ontogeny of personality traits in the red junglefowl, Gallus gallus. Behav Ecol 27:484-493. https://doi.org/10.1093/beheco/arv177

Favati A, Løvlie H, Leimar O (2017) Individual aggression, but not winner-loser effects, predicts social rank in male domestic fowl. Behav Ecol 28:874-882. https://doi.org/10.1093/beheco/arx053

Forkman B, Boissy A, Meunier-Salaun MC, Canali E, Jones RB (2007) A critical review of fear tests used on cattle, pigs, sheep, poultry and horses. Physiol Behav 3:340-374. https://doi.org/10.1016/j. physbeh.2007.03.016

Fox RA, Ladage LD, Roth TC, Pravosudov VV (2009) Behavioural profile predicts dominance status in mountain chickadees, Poecile gambeli. Anim Behav 77:1441-1448. https://doi.org/10.1016/j. anbehav.2009.02.022

Francia N, Cirulli F, Chiarotti F, Antonelli A, Aloe L, Alleva E (2006) Spatial memory deficits in middle-aged mice correlate with lower exploratory activity and a subordinate status: role of hippocampal neurotrophins. Eur J Neurosci 23:711-728

Gahr M (2001) Distribution of sex steroid hormone receptors in the avian brain: functional implications for neural sex differences and sexual behaviors. Microsc Res Tech 55:1-11. https://doi.org/10.1002/jemt. 1151

Gallup GG Jr (1979) Tonic immobility as a measure of fear in domestic fowl. Anim Behav 27:316-317. https://doi.org/10.1016/00033472(79)90159-3

Garnham L, Løvlie H (2018) Sophisticated fowl: the complex behaviour and cognitive skills of chickens and red junglefowl. Behav Sci 8:13. https://doi.org/10.3390/bs8010013

Greggor AL, Thornton A, Clayton NS (2015) Neophobia is not only avoidance: Improving neophobia tests by combining cognition and ecology. Curr Opin Behav Sci.6:82-89 https://doi.org/10.1016/j. cobeha.2015.10.007.

Guenther A, Brust V (2017) Individual consistency in multiple cognitive performance: behavioural versus cognitive syndromes. Anim Behav 130:119-131. https://doi.org/10.1016/j.anbehav.2017.06.011

Guhl AM (1968) Social behavior of the domestic fowl. Trans Kans Acad Sci 71:379-384. https://doi.org/10.2307/3627156

Guido JM, Biondi LM, Vasallo AI, Muzio RN (2017) Neophobia is negatively related to reversal learning ability in females of a generalist bird of prey, the Chimango Caracara, Milvago chimango. Anim Cogn 20:591-602. https://doi.org/10.1007/s10071-017-1083-

Guillette LM, Naguib M, Griffin AS (2017) Individual differences in cognition and personality. Behav Process 134:1-3. https://doi.org/ 10.1016/j.beproc.2016.12.001

Harding EJ, Paul ES, Mendl M (2004) Animal behaviour: cognitive bias and affective state. Nature 427:312. https://doi.org/10.1038/ $427312 \mathrm{a}$

Hareiman PL (1947) The new dictionary of psychology. Philosophical Library, New York

Hey JD (1984) The economics of optimism and pessimism. Kyklos 37: 181-205. https://doi.org/10.1111/j.1467-6435.1984.tb00748.x

Hübner F, Fichtel C, Kappeler PM (2018) Linking cognition with fitness in a wild primate: fitness correlates of problem-solving performance and spatial learning ability. Proc R Soc B 373:20170295. https://doi. org/10.1098/rstb.2017.0295

Huntingford FA (1976) The relationship between antipredator behaviour and aggression among conspecifics in the three-spined stickleback, Gasterosteus aculeatus. Anim Behav 24:245-260. https://doi.org/ 10.1016/S0003-3472(76)80034-6

Jackson WM (1991) Why do winners keep winning? Behav Ecol Sociobiol 28:271-276

Johnson DDP, Fowler JH (2011) The evolution of overconfidence. Nature 477:317-320. https://doi.org/10.1038/nature10384

Jones RB (1986) The tonic immobility reaction of the domestic fowl: a review. World Poultry Sci J 42:82-96

Jones RB (1996) Fear and adaptability in poultry: insights, implications and imperative. World Poultry Sci J 52:131-174. https://doi.org/10. 1079/WPS19960013

Kar F, Whiting MJ, Noble DWA (2016) Influence of prior contest experience and level of escalation on contest outcome. Behav Ecol Sociobiol 70:1679-1687. https://doi.org/10.1007/s00265-0162173-4

Kar F, Whiting MJ, Noble DWA (2017) Dominance and social information use in a lizard. Anim Cogn 20:805-812. https://doi.org/10. 1007/s10071-017-1101-y

Keynan O, Ridley AR, Lotem A (2016) Task-dependent differences in learning by subordinate and dominant wild Arabian babblers. Ethology 122:1-12. https://doi.org/10.1111/eth.12488

Koolhaas JM, Korte SM, de Boer SF, van der Vegt BJ, van Reenen CG, Hopster H, de Jong IC, Ruis MA, Blokhuis HJ (1999) Coping styles in animals: current status in behavior and stress-physiology. Neurosci Biobehav Rev 23:925-935. https://doi.org/10.1016 S0149-7634(99)00026-3

Korzan WJ, Øverli Ø, Summers CH (2006) Future social rank: forecasting status in the green anole (Anolis carolinensis). Acta Ethol 9:4857. https://doi.org/10.1007/s10211-006-0015-5

Kruijt JP (1964) Ontogeny of social behaviour in Burmese red junglefowl (Gallus gallus spadiceus) Bonnaterre. Behaviour Suppl 1:1-201

Langley EJG, van Horik JO, Whiteside MA, Madden JR (2018) Group social rank is associated with performance on a spatial learning task. R Soc Open Sci 5:171475. https://doi.org/10.1098/rsos.171475

Ligon JD, Thornhill R, Zuk M, Johnson K (1990) Male-male competition, ornamentation and the role of testosterone in sexual selection in red jungle fowl. Anim Behav 40:367-373. https://doi.org/10.1016/ S0003-3472(05)80932-7

Losecaat Vermeer AB, Riečanský I, Eisenegger C (2016) Competition, testosterone, and adult neurobehavioral plasticity. Prog Brain Res 229:213-238. https://doi.org/10.1016/bs.pbr.2016.05.004

MacLean EL, Hare B, Nunn CL et al (2014) The evolution of self-control. P Natl Acad Sci USA 20:E2140-E2148. https://doi.org/10.1073/ pnas.1323533111

Matzel LD, Kolata S, Light K, Sauce B (2017) The tendency for social submission predicts superior cognitive performance in previously 
isolated male mice. Behav Process 134:12-21. https://doi.org/10. 1016/j.beproc.2016.07.011

Mendl M, Burman OHP, Paul ES (2010) An integrative and functional framework for the study of animal emotion and mood. Proc R Soc Lond B 277:2895-2904. https://doi.org/10.1098/rspb.2010.0303

Mills AD, Crawford LLDM, Faure JM (1997) The behavior of the Japanese or domestic quail Coturnix japonica. Neurosci Biobehav Rev 21:261-281

Moraga-Amaro R, van Waarde A, Doorduin J, de Vries EFJ (2017) Sex steroid hormones and brain function: PET imaging as a tool for research. J Neuroendocrinol 30:e12565. https://doi.org/10.1111/ jne. 12565

Nautiyal K, Wall M, Wang S, Magalong V, Ahmari S, Balsam P, Blanco C, Hen R (2017) Genetic and modeling approaches reveal distinct components of impulsive behavior. Neuropsychopharmacology 42: 1182-1191. https://doi.org/10.1038/npp.2016.277

Niemelä PT, Dingemanse NJ (2018) On the usage of single measurements in behavioural ecology research on individual differences. Anim Behav 145:99-105. https://doi.org/10.1016/j.anbehav.2018. 09.012

Nygren TE, Isen AM, Taylor PJ, Nygren JD (1996) The influence of positive affect on the decision rule in risk situations: focus on outcome (and especially avoidance of loss) rather than probability. Organ Behav Hum Dec 66:59-72. https://doi.org/10.1006/obhd. 1996.0038

Perry S, Godoy I, Lammers W, Lin A (2017) Impact of personality traits and early life experience on timing of emigration and rise to alpha male status for wild male white-faced capuchin monkeys (Cebus capucinus) at Lomas Barbudal Biological Reserve, Costa Rica. Behaviour 154:195-226. https://doi.org/10.1163/1568539X00003418

Pravosudov VV, Mendoza SP, Clayton NS (2003) The relationship between dominance, corticosterone, memory, and food caching in mountain chickadees (Poecile gambeli). Horm Behav 44:93-102. https://doi.org/10.1016/S0018-506X(03)00119-3

R Core Team (2019) R: A language and environment for statistical computing. R Foundation for Statistical Computing, Viennaa https:// www.R-project.org/

Réale D, Dingemanse NJ, Kazem AJN, Wright J (2010) Evolutionary and ecological approaches to the study of personality. Philos Trans R Soc B 365:3937-3946. https://doi.org/10.1098/rstb.2010.0222

Reichert MS, Quinn JL (2017) Cognition in contests: mechanisms, ecology, and evolution. Trends Ecol Evol 32:773-785. https://doi.org/ $10.1016 /$ j.tree.2017.07.003

Riechert SE, Hedrick AV (1993) A test for correlations among fitnesslinked behavioural traits in the spider, Agelenopsis aperta (Araneae, Agelenidae). Anim Behav 46:669-675. https://doi.org/10.1006/ anbe.1993.1243

Scheier MF, Carver CS (1985) Optimism, coping, and health: assessment and implications of generalized outcome expectancies. Health Psychol 4:219-247. https://doi.org/10.1037//0278-6133.4.3.219

Shaw RC, Boogert NJ, Clayton NS, Burns KC (2015) Wild psychometrics: evidence for 'general' cognitive performance in wild New Zealand robins, Petroica longipes. Anim Behav 109:101-111. https://doi.org/10.1016/j.anbehav.2015.08.001

Shettleworth SJ (2010) Cognition, evolution, and behavior. Oxford University Press, Oxford

Sih A, Del Giudice M (2012) Linking behavioural syndromes and cognition: a behavioural ecology perspective. Philos Trans R Soc B 367:2762-2772. https://doi.org/10.1098/rstb.2012.0216
Sih A, Bell A, Johnson JC (2004) Behavioral syndromes: an ecological and evolutionary overview. Trends Ecol Evol 19:372-378. https:// doi.org/10.1016/j.tree.2004.04.009

Sih A, Bell AM (2008) Insights for Behavioral Ecology from Behavioral Syndromes. Adv Study Behav. 2008; 38:227-281 https://doi.org/10. 1016/S0065-3454(08)00005-3.

Sorato E, Zidar J, Garnham L, Wilson A, Løvlie H (2018) Heritabilities and co-variation among cognitive traits in red junglefowl. Philos Trans R Soc B 373:20170285. https://doi.org/10.1098/rstb.2017. 0285

Spritzer MD, Meikle DB, Solomon N (2004) The relationship between dominance rank and spatial ability among male meadow voles (Microtus pennsylvanicus). J Comp Psychol 118:332-339. https:// doi.org/10.1037/0735-7036.118.3.332

Uskul AK, Greenglass E (2005) Psychological wellbeing in a TurkishCanadian sample. Anxiety Stress Coping 18:269-278. https://doi. org/10.1080/10615800500205983

van Horik JO, Langley EJG, Whiteside MA, Laker PR, Beardsworth CE, Madden JR (2018) Do detour tasks provide accurate assays of inhibitory control? Proc R Soc B 373:20170281. https://doi.org/10. 1098/rspb.2018.0150

van Oers K, Klunder M, Drent PJ (2005) Context dependence of personalities: risk-taking behavior in a social and a nonsocial situation. Behav Ecol 16:716-720. https://doi.org/10.1093/beheco/ari045

Verbeek MEM, Boon A, Drent PJ (1996) Exploration, aggressive behaviour and dominance in pair-wise confrontations of juvenile male great tits. Behaviour 133:945-963. https://doi.org/10.1163/ 156853996 X00314

Wade J (1999) Sexual dimorphisms in avian and reptilian courtship: two systems that do not play by mammalian rules. Brain Behav Evol 54: 15-27. https://doi.org/10.1159/000006608

Wascher CAF, Kulahci IG, Langley EJG, Shaw RC (2018) How does cognition shape social relationships? Philos Trans R Soc B 373: 20170293. https://doi.org/10.1098/rstb.2017.0293

Waters EA (2008) Feeling good, feeling bad, and feeling at-risk: a review of incidental affect's influence on likelihood estimates of health hazards and life events. J Risk Res 11:569-595. https://doi.org/10. 1080/13669870701715576

Zidar J, Balogh A, Favati A, Jensen P, Leimar O, Løvlie H (2017a) A comparison of animal personality and coping styles in the red junglefowl. Anim Behav 130:209-220. https://doi.org/10.1016/j. anbehav.2017.06.024

Zidar J, Sorato E, Malmqvist AM, Jansson E, Rosher C, Jensen P, Favati A, Løvlie H (2017b) Early experience affects adult personality in the red junglefowl: a role for cognitive stimulation? Behav Process 134: 78-86. https://doi.org/10.1016/j.beproc.2016.06.003

Zidar J, Campderrich I, Jansson E, Wichman A, Winberg S, Keeling L, Løvlie H (2018a) Environmental complexity buffers against stressinduced negative judgement bias in female chickens. Sci Rep 8: 5404. https://doi.org/10.1038/s41598-018-23545-6

Zidar J, Balogh A, Favati A, Jensen P, Leimar O, Sorato E, Løvlie H (2018b) The relationship between learning speed and personality is age- and task-dependent in the red junglefowl. Behav Ecol Sociobiol 72:168. https://doi.org/10.1007/s00265-018-2579-2

Zidar J, Balogh A, Leimar O, Løvlie H (2019) Generalization of learned preference covaries with behavioral flexibility in red junglefowl chicks. Behav Ecol 30:1375-1381. https://doi.org/10.1093/beheco/ arz088

Publisher's note Springer Nature remains neutral with regard to jurisdictional claims in published maps and institutional affiliations. 